\title{
DISTRIBUCIÓN Y CONSERVACIÓN DE DOS ESPECIES DE ORQUÍDEAS EN EL DEPARTAMENTO DEL META, COLOMBIA
}

Fecha de recepción: 29 de abril de 2016 • Fecha de Evaluación: 18 de junio de 2016 • Fecha de aceptación: 4 de julio de 2016 - Disponible en línea: 25 de julio de 2016

\section{DISTRIBUTION AND CONSERVATION OF TWO SPECIES OF ORCHIDS IN META DEPARTMENT, COLOMBIA}

Oscar Iban Hernández Castañeda', Miguel Macgayver Bonilla Morales², Julián F. Cárdenas

\section{RESUMEN}

En Colombia existen alrededor de 4.270 especies de orquídeas distribuidas en ambientes que van desde los páramos hasta desiertos. En este país, Prosthechea vespa y Encyclia cordigera presentan usos en colecciones personales, para decorar jardines y exposiciones nacionales o internacionales, aunque, por sus relaciones ecosistémicas estas especies son importantes en ambientes naturales. Por tal motivo, la presente investigación tuvo como objetivo establecer la distribución y aspectos relacionados con la conservación de P. vespa y E. cordigera en el departamento del Meta. De esta manera, se revisó material de herbario, literatura científica y salidas de campo para la conformación de la base de datos y análisis de la información espacial con DIVA-GIS ${ }^{\circledR}$, incluyendo mapas de distribución y áreas protegidas. Simultáneamente, se colectaron frutos nativos para su propagación in vitro. La distribución de las especies se registra en las bioregiones del piedemonte en un rango de 400 a 1000 msnm en los municipios de Villavicencio, Restrepo y Cumaral asociadas a bosques húmedos y secos. La germinación in vitro de E. cordigera fue entre 20-24 semanas y la de $P$. vespa fue a las 10 semanas, pero el proceso de organogénesis se presentó sólo en $E$. cordigera catalogando este método como estrategia de conservación de germoplasma ex situ. De esta manera sólo se pudo generar protocolos para la multiplicación in vitro de E. cordigera. Además, ambas especies poseen una distribución limitada y pocos datos de ocurrencia, por lo que el piedemonte metense puede ser considerado como zona de conservación.

Palabras claves: Encyclia cordigera, conservación ex situ, conservación in situ, Prosthechea vespa, SIG.

1 Grupo ISAF, Universidad de los Llanos, 2Grupo de Investigación en Orquídeas, Ecología y Sistemática Vegetal, Universidad Nacional de Colombia, Sede Palmira.

2 Autor corresponsal: mmbonillam@unal.edu.co 


\section{ABSTRACT}

In Colombia there around 4270 species of orchids distributed in environments ranging from the moors to deserts. In this country Prosthechea vespa and Encyclia cordigera has uses in personal collections, to decorate gardens and in national or international exhibitions, thanks to their ecological relationships these species are important in natural environments. Therefore, this study aimed to establish the distribution and conservation aspects of E. cordigera and P. vespa in the department of Meta. Thus, herbarium material, literature and field for forming the database and analysis of spatial information with DIVA-GIS ${ }^{\circledR}$, which included distribution maps and protected areas was conducted. Simultaneously, native fruits for in vitro propagation were collected. The distribution of species was recorded in the piedemont bioregions in a range of 400 to $1000 \mathrm{~m}$ in the municipalities of Villavicencio, Restrepo and Cumaral associated with wet and dry forests. The in vitro germination of E. cordigera (20-24 weeks) and $P$. vespa (10 weeks) and the process of organogenesis occurs only in E. cordigera strategy as ex situ conservation of germplasm. Thus he could only generate protocols for in vitro multiplication of E. cordigera. In addition, both species have limited distribution and few occurrence data, so the piedmont metense can be considered conservation area.

Key words: conservation ex situ, conservation in situ, Encyclia cordigera, Prosthechea vespa, SIG.

\section{INTRODUCCIÓN}

Las orquídeas han sido objeto de innumerables estudios, los que más se destacan son los taxonómicos y biológicos, que permiten identificar las especies e indicar la diversidad de una zona por las relaciones que desarrollan con otros organismos a lo largo de su ciclo de vida (Cox, 2013). La mayoría de las orquídeas tienen hábito epífito, por lo que tienen adaptaciones morfofisiológicas que dependen de las características del árbol hospedero (forófito) y de las condiciones ambientales donde estos se distribuyen (Valencia, 2014). La relación simbiótica entre las orquídeas con algunos hongos micorrízicos para su germinación y desarrollo (Granados-Sánchez et al. 2003), y con especies de insectos polinizadores y defensores como las hormigas, permiten que las especies coexistan simbióticamente en la naturaleza, de tal manera, la desaparición de una implica la existencia de la otra.
En Colombia, las orquídeas prosperan desde los páramos hasta altitudes sobre el nivel del mar y desde zonas secas hasta bosques muy lluviosos, distribuidas en diferentes nichos ecológicos (Díaz et al. 2004; Martínez et al. 2015). Esta multiplicidad de ecosistemas favorece el desarrollo de una gran diversidad de especies de orquídeas. No obstante, las actividades antropogénicas han generado perdida de la diversidad biológica (Andrade, 2011). Colombia alberga aproximadamente 4.270 especies de orquídeas, de estas, cerca de la tercera parte son endémicas (Betancur et al. 2015), y con tan solo 375 especies nativas se han estudiado para conocer su estatus de conservación (Calderón-Sáenz, 2006).

El primer método para la germinación asimbiótica de orquídeas in vitro fue realizado por Knudson (1921), quien demostró que era posible 
la germinación de orquídeas sobre un medio simple que contuviera minerales y azucares. De esta manera, contribuyó con la formulación de medios para la propagación in vitro de orquídeas sin necesidad de hongos micorrízicos (Salazar, 2012). Adicionalmente, la conservación in vitro, permite obtener bajo condiciones controladas material libre de enfermedades en espacios reducidos en un menor tiempo (Calva y Pérez, 2005; Bonilla y Hernández, 2012).

Los recursos genéticos tienen un importante valor para el país, y sus inventarios son una herramienta fundamental para el análisis del estado actual y potencial de ellos en la toma de decisiones sobre medidas de conservación y renovación ( $\mathrm{Va}$ lencia et al. 2010; Bonilla, Mancipe y Aguirre, 2015). Por tal motivo, las colecciones mantenidas en los bancos de germoplasma son el resultado de estrategias de conservación ex situ, cuyo complemento ideal es la conservación in situ (Calderón-Sáenz, 2006). Este enfoque complementario es necesario, ya que las colecciones ex situ nunca podrán contener todos los acervos de genes, y el germoplasma mantenido in situ continúa adaptándose a los cambios ambientales. La diversidad que se mantiene in situ es, a menudo, mucho menos accesible que la de las colecciones y su conservación a largo plazo es menos segura (Engels y Visser, 2007).

Dentro de las especies que poco se conocen las dinámicas de distribución y conservación en el Meta, se encuentra Prosthechea vespa (Vell.) W.E. Higgins y Encyclia cordigera (Kunth) Dressler, que a su vez son utilizadas en colecciones ornamentales, y en algunas ocasiones son extraídas de su hábitat natural por tráfico ilegal de plantas. Por tal motivo, el objetivo de esta investigación fue conocer aspectos de la distribución relacionados con áreas protegidas y procesos de propagación in vitro de $P$. vespa y E. cordigera, para el establecimiento de planes y estrategias de conservación in situ y ex situ.

\section{MATERIALES Y MÉTODOS}

\section{Área de estudio}

El estudio se realizó en Colombia, en los municipios de Villavicencio, Restrepo, Cumaral y Acacias, Puerto López, San Juanito y el Calvario que pertenecen al departamento del Meta. Dentro de las principales bioregiones del Meta: Altillanura, Piedemonte, Piedemonte bajo andino y alto andino $y$, Andes.

Herbarios, literatura y salidas de campo

Se consultó los herbarios nacionales como LLANOS de la Universidad de los Llanos, COL y COAH y se accedió a la revisión bibliográfica reportada para P. vespa y E. cordigera en Colombia de López (2011), Ortiz y Uribe (2014), Bernal et al. (2015) y Betancur et al. (2015). Adicionalmente, para sumar el mayor número de registros se realizaron salidas de campo en bosques primarios y caminos de carretera durante el periodo 2013-2015. Esto con la finalidad de establecer una base de datos para el análisis de resultados geográficos.

\section{Distribución}

Para la ocurrencia de especies se utilizó la metodología utilizada por Hijmans et al. (2001) en el programa DIVA-GIS ${ }^{\odot}$ versión 7.5 con la finalidad de establecer la distribución mediante puntos en el mapa del departamento del Meta. Además, se sobrepuso la capa del mapa de áreas protegidas con zonas de conservación in situ del área de estudio.

\section{Propagación in vitro}

Para la germinación in vitro se colectaron manualmente cápsulas maduras de plantas in situ que fueron almacenadas en bolsas Ziplot hasta llevarlas al laboratorio de cultivo de tejidos vegetales de la Universidad de los Llanos, donde se inició el protocolo de desinfección para la siembra in vitro. Las 
capsulas fueron lavadas con detergente comercial al $1 \%$, con posterior lavado en agua a chorro. Una vez limpias las capsulas, estas fueron desinfectadas mediante la inmersión con $\mathrm{NaOCl}$ al 1\% durante 10 minutos y sumergidas en agua destilada estéril con 3 lavados para remover los residuos del producto. Posteriormente, fueron transportadas a la cámara de flujo laminar y sumergidas en alcohol al 70\% durante 1 minuto, seguido de 3 lavados en agua destilada estéril. Luego a las capsulas se les realizaron cortes transversales para la extracción de las semiIlas, las cuales fueron finalmente sembradas en los frascos que contenían los medios de cultivo: i) MS y ii) MS suplementado con $100 \mathrm{~mL} / \mathrm{L}$ de agua de coco (AC), a ambos medios se les adicionó 0,5\% de Carbón activado, $30 \mathrm{gr} / \mathrm{L}$ de azúcar y 2,0gr/L de Phytagel. Realizada la siembra, los frascos fueron almacenados en un cuarto de incubación bajo condiciones de 16/8 horas luz y noche, intensidad lumínica de $3000 \mathrm{Lux}, 27^{\circ} \mathrm{C}$ de temperatura y $60 \%$ de humedad relativa. Finalmente se determinó la germinación asimbiótica de la semilla, y se calificó de acuerdo con las fases de desarrollo para las semillas de orquídeas propuesta por Johnson y Kane, (2007).

\section{RESULTADOS Y DISCUSIÓN}

En algunas localidades visitadas no se logró encontrar las especies en estado de floración, y en aquellos donde presentaron floración, como el Caney alto, Buena vista, Montecarlo y Bavaria, se observó que la cantidad de plantas localizadas en el mismo árbol fue de 2 hasta 10 plantas en $P$. vespa y de 2 a 3 plantas en E. cordigera (Fig. 1, 2).

\section{Distribución}

La distribución de las especies $E$. cordigera y $P$. vespa se encuentra concentrada en la zona de Piedemonte de la cordillera Oriental, flanco oriental, en los municipios de Villavicencio, Restrepo y Cumaral con elevaciones que van desde los 200 hasta 1.000 msnm (Figura 3). De acuerdo con Pabón-Caicedo et al. (2001), el piedemonte Llanero presenta un clima tropical lluvioso y estas condiciones, principalmente de humedad relativa alta, favorecen el desarrollo de diferentes especies epifitas (Guerra y Huamani, 1995; Granados-Sánchez et al. 2003), entre estas, permite fácil desarrollo de P. vespa y E. cordigera. En la Figura 3, ninguna de estas

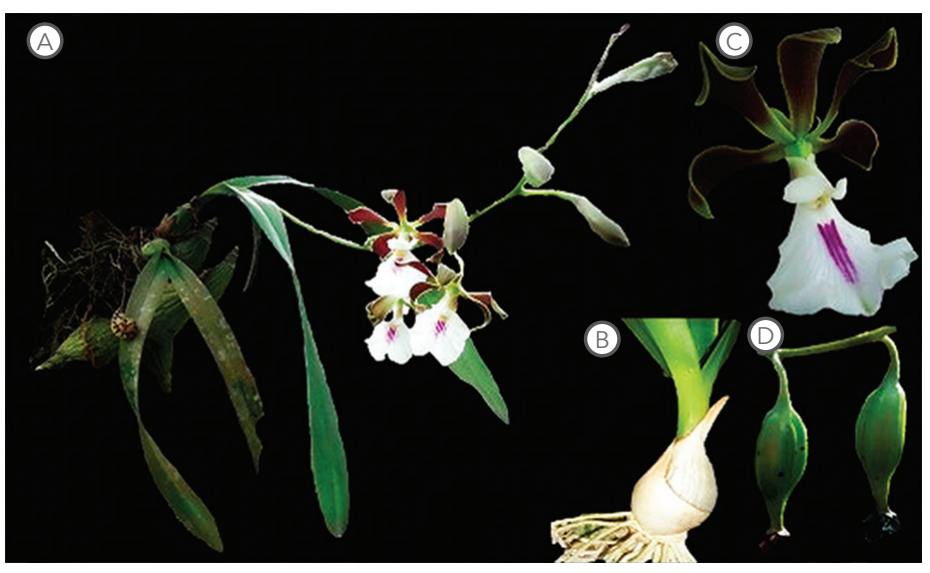

Figura 1. Encyclia cordigera. a) Planta con inflorescencia; b) vainas; c) flor y d) fruto. Fotos: Oscar Hernández, Miguel Bonilla-M y Johan Mosquera. 


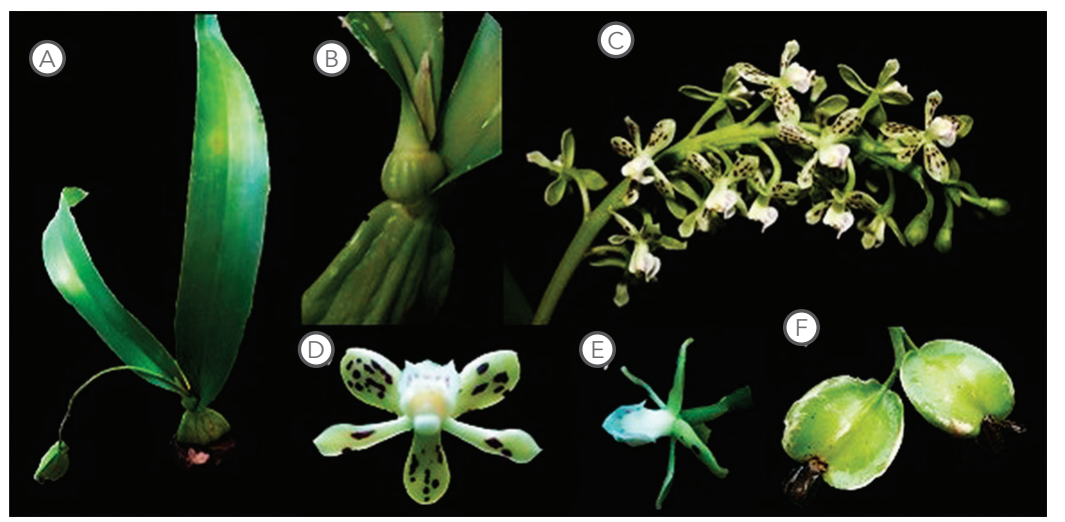

Figura 2. Prosthechea vespa a) planta; b) espata; c) Inflorescencia; d), e) flor y f) fruto. Fotos: a), b), d), e) y f) Oscar Hernández y Miguel Bonilla-M; c), Álvaro Velásquez. especies se encuentra dentro de las áreas protegidas o de conservación, sin embargo, algunas de sus poblaciones están muy cercanas para establecer áreas de repoblación en zonas cercanas.

En el trabajo de Quiroga et al. (2010), P. vespa presenta un rango altitudinal entre los 190-3.000 msnm y preferiblemente se encuentra en formaciones vegetales de bosque de piedemonte, bosque montano húmedo y bosque de inundación. Por su parte, Berry et al. (2003) reportan que esta especie se distribuye en zonas de bosque húmedo a bosques lluviosos que van desde los 0 a 1.200 msnm. Por otro lado, E. cordigera prefiere zonas de bosques secos y caducifolios que van desde los 50 a 400 msnm, y se distribuye desde el norte de Venezuela, Colombia, Trinidad y Tobago y Centro América (Berry, Yatskievych, y Holst, 2003) y es comúnmente encontrada en potreros arbolados y despejados asociados a diferentes especies de árboles (Fotosíntesis, 2012). Estos resultados coinciden parcialmente en ambas especies para los datos registrados en el Meta, porque en municipios como El Calvario y San Juanito (elevación $>1700$ msnm), no se observó ninguna de las dos especies. También se han reportado individuos de E. cordigera y $P$. vespa en los municipios de Lejanías (Hasta
1000 msnm) y Mapiripán (<300 msnm) respectivamente (Rodríguez, 2010).

\section{Propagación in vitro}

La germinación in vitro se presentó en el medio de cultivo MS + AC suplementado con agua de coco, mientras que para el medio MS sin ninguna adición se observó una fenolización y nulo desarrollo de los embriones. La fenolización es un problema común que se presenta en el cultivo in vitro conocido como oxidación u oscurecimiento de tejidos, ocurre cuando el tejido se encuentra senescente, se expone a lesiones, sustancias abrasivas o factores como intensidad de luz u composición del medio de cultivo que generan un estrés oxidativo y nitrosativo en las células que puede llevarlas a la muerte (Azofeifa, 2009). Por lo que la concentración elevada de uno de los compuestos empleados como el agua de coco pudieron haber incidido en el desarrollo del embrión para ambas especies.

En E. cordigera la germinación in vitro se presenta a partir de las 20 a 24 semanas después de incubadas y a las 10 semanas para P. vespa. No obstante, el proceso de organogénesis se observó sólo en E. cordigera, lo cual postula este método 
como estrategia de conservación de germoplasma ex situ para esta especie. Conforme con las fases de desarrollo de las semillas de orquídeas de Johnson y Kane (2007), se logró obtener plántulas hasta la fase 5 (presencia de 2 o más hojas) en $E$. cordigera, mientras que para $P$. vespa, se desarroIlaron hasta la fase 1 (expansión del embrión, ruptura de la testa) (Fig. 4, 5).

Estos resultados no concuerdan con lo obtenido por Salazar y Orlando (2012), quienes evaluaron tres diferentes medios sobre la germinación in vitro en $P$. vespa [MS básico, MS+ agua de coco (AC) y $\mathrm{MS}+$ jugo de piña (JP)], en condiciones de 16 horas de fotoperiodo, $25 \mu \mathrm{mol} / \mathrm{m}^{2} . \mathrm{s}, 21 \pm 2{ }^{\circ} \mathrm{C}$ y $60 \%$ de humedad relativa, logrando obtener una germinación y desarrollo de las semillas hasta la fase 3 con el medio MS básico, hasta la fase 4 con el medio $\mathrm{MS}+\mathrm{AC}$ y con el medio MS+JP logran obtener semillas desarrolladas hasta la fase 5 en $P$. vespa.

Los resultados obtenidos en $P$. vespa y su nulo desarrollo de las semillas en los medios MS, posiblemente, podrían estar asociados al efecto de la concentración empleada de carbón activo en el medio de cultivo o la combinación de factores como el genotipo, la composición del medio de cultivo e incubación, entre otros (Cañal et al. 2001). El carbón activo es empleado en el cultivo de tejidos como agente antioxidante, sin embargo,

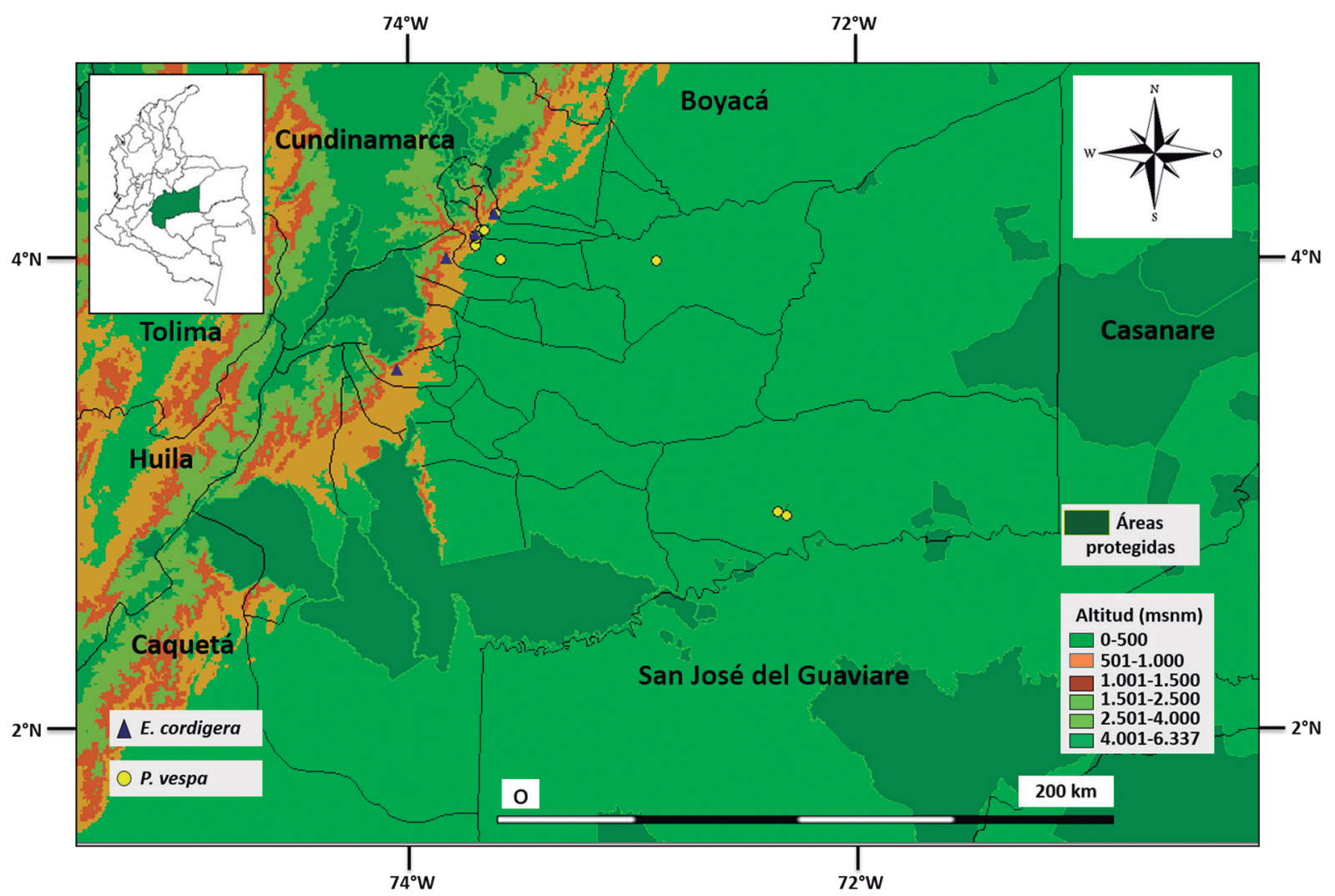

Figura 3. Mapa de distribución y áreas protegidas de E. cordigera y P. vespa en el departamento del Meta. 
puede actuar como inhibidor de crecimiento afectando la absorción de nutrientes por la plántula (Pedroza-Manrique, 2007; Borgues y Sosa, 2008). En especies del género Dioscorea, como D. alata, los valores del número de nudos durante el transcurso del tiempo demuestran una tendencia a la disminución a medida que aumenta la incorporación de carbón activado en el medio de cultivo (Borgues y Sosa). En orquídeas, Pedroza-Manrique (2007), reporta que una adición de 0,5\% de carbón activo, a los medios de cultivos empleados interfiere negativamente sobre la germinación in vitro de las semillas de Masdevallia auropurpurea.

Estudios realizados por Rodríguez et al. (2007), demuestran que la germinación in vitro en especies de orquídeas (Bletia patula Encyclia gravida, Encyclia oxypetala, Encyclia phoenicea, Epidendrum nocturnum, Epidendrum secundum, Epidendrum wrigthii, Eulophia alta, Oncydium luridum, Phaius tancarvillae, Physinga polygonatum, Polystachya concreta, Polystachya foliosa, Prosthechea fragans y Schomburgkia lyonsii) sembradas en medios de cultivo MS, Knudson, Vacing y Went y Morel suplementados con AC 10\%, sacarosa $2 \%$ y 0,0-0,15\% de carbón activo, es favorecida por la adición de este producto, dado a que incrementa la aireación del medio de cultivo. Sumado al efecto antioxidante, obtiene para las especies evaluadas una germinación del $53 \%$ y $47 \%$ del total de las especies germinadas en los medios MS y Knudson, mientras que para los medios Morel y Vacing y Went logran obtener un $40 \%$ y $27 \%$ respectivamente; observando la especie E. oxypetala como la más precoz en germinar en un periodo de 6 semanas (Rodríguez et al. 2007).

Pedroza-Manrique 2009, reporta que el carbón activado estimula los procesos de desarrollo morfogénico de raíces y protocormos que potencian el efecto del AIA (Ácido Indolacético), obteniendo de la interacción del carbón activado en

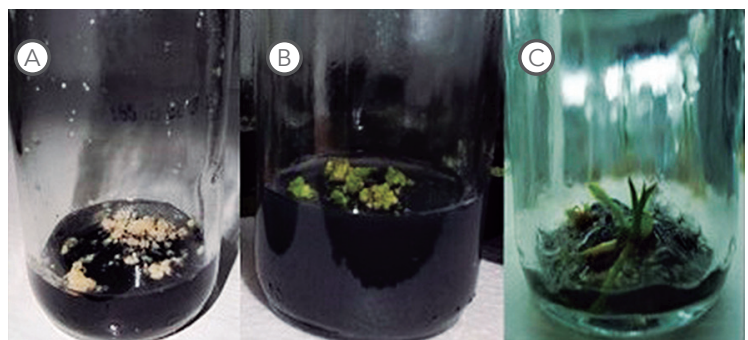

Figura 4. Fases de desarrollo en E. cordigera a) fase 0 ; b) fase 1 y c) fase 5. Fotos Oscar Hernández y Miguel Bonilla-M.

concentraciones de 0,5 y 1,0\% con 0,5 mg.L-1 de AIA, resultados positivos en el desarrollo de protocormos de Epidendrum elongatum bajo condiciones in vitro, mientras que la interacción del BAP (Bencil Amino Purina) en concentraciones de 0,5 y 1,0 mg.L-1 se determina resultados no tan favorables, en cuanto al grado de desarrollo de los protocormos y con mayor estructuras foliares.

\section{CONCLUSIONES}

Las poblaciones nativas de E. cordigera y P. vespa del Meta, presentan una distribución limitada y pocos datos de ocurrencias, por lo que se hace

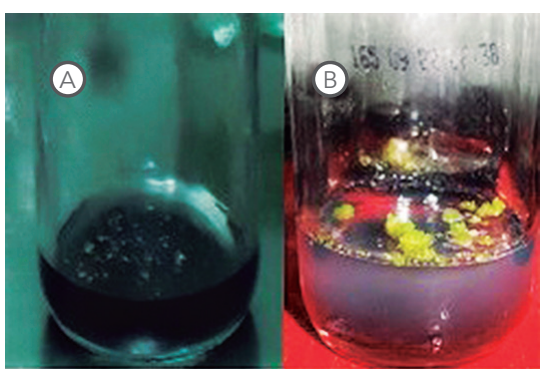

Figura 5. Fases de desarrollo en P. vespa a) fase 0 y b) fase 1. Fotos Oscar Hernández y Miguel Bonilla-M. 
necesario realizar esfuerzos para conservarlas in situ, mediante estrategias en áreas protegidas nacionales como las Reservas Forestales de Villavicencio; y ex situ, mediante planes de conservación in vitro. Esta propuesta conjunta permitirá mantener la variabilidad genética de los genotipos locales.

\section{AGRADECIMIENTOS}

Los autores expresan sus agradecimientos a Johan Mosquera Hernández por la participación y la colaboración en las colectas. Además, al personal del laboratorio de Biotecnología Vegetal de la Universidad de los Llanos y al grupo de investigación Horizonte Mediático por el apoyo de espacios y materiales en el desarrollo del proyecto.

\section{REFERENCIAS}

1 Azofeifa A. 2009. Problemas de oxidación y oscurecimiento de explantes cultivados in vitro. Agronomía Mesoamericana. 20(1): 153-175.

2 Bernal R, Grasdstein S y Celis M. 2015. Catálogo de plantas y líquenes de Colombia [online], Colombia, Instituto de Ciencias Naturales de Colombia, Bogotá. Disponible: http://catalogoplantascolombia.unal.edu.co

3 Berry P, Yatskievych Ky Holst B. 2003. Flora of the Venezuelan Guayana. United States: Missouri botanical garden.765 pp.

4 Betancur J, Sarmiento H, Toro-González L y Valencia J. 2015. Plan para el estudio y la conservación de orquídeas en Colombia. Universidad Nacional de Colombia, Facultad de Ciencias, Instituto de Ciencias Naturales y Ministerio de Ambiente. 336 pp.

5 Bonilla M y Hernández O. 2012. Propagación in vitro de ñame (Dioscorea spp.): una perspectiva en la producción masiva de plántulas y conservación de germoplasma. Agronomía. 20 (2): 65-72.

6 Bonilla M, Mancipe C y Aguirre C. 2015. Conservación in vitro: una perspectiva para el manejo de los Recursos Fitogenéticos. Revista de Investigación Agraria y Ambiental. 6 (1): 67-81.

7 Borges M y Sosa Y. 2008. Efectos de la adición de diferentes concentraciones de carbón activado sobre la multiplicación in vitro de ñame. Biotecnología Vegetal. 8(2): 87-90. 
8 Calderón-Sáenz E. 2006. Libro rojo de plantas de Colombia. Vol 6. Orquídeas. Primera parte. Bogota, Colombia: Serie Libros Rojos de Especies Amenazadas de Colombia. Instituto Alexander von Humboldt - Ministerio de Ambiente, Vivienda y Desarrollo Territorial. 828pp.

9 Camargo C y Delgado C. 2006. Flora Orchidaceae de la Mesa de los Santos (PiedecuestaSantander). Tesis para optar el título de Biólogo. Bucaramanga- Santander. 306 pp.

10 Cañal M, Rodríguez R, Fernández B, SánchezTames R y Majada J. 2001. Fisiología del cultivo in vitro. Biotecnología Vegetal. 1: 3-9.

11 Calva G y Pérez J. 2005. Cultivo de células y tejidos vegetales: fuente de alimentos del futuro. Revista Digital Universitaria. 6 (11): 1-16.

12 Cox, L. 2013. Orquídeas: importancia y uso en México. Bioagrociencias. 6(2): 4-7.

13 Díaz J, Solano F, Sánchez L y Espinoza F. 2004. Riqueza y distribución de las orquídeas en la Provicincia de Pamplona. Bistua. 2(1): 106-112.

14 Engels J y Visser L. 2007. Guía para el manejo eficaz de un banco de germoplasma. Manuales para bancos de germoplasma No 6. Biodiversity International, Roma: Italia. 130 pp.

15 Espinosa, F. 2012. Caracterización de las especies del género Prosthechea (orchidaceas) presentes en Colombia. Trabajo de tesis para optar el título de Biólogo. Bogotá: Pontifica Universidad Javeriana. 45 pp.
16 Fotosíntesis. (2012). Proyecto Oleoducto Bicentenario. Guia ilustrada de las plantas epífitas del tramo Araguaney-Banadía. Bogota: Colombia. 116 pp.

17 Granados-Sánchez D, López-Ríos G, Hernández-García M y Sánchez-González, A. 2003. Ecología de las plantas epífitas. Chapingo serie ciencias forestales y del ambiente. 9(2): 101-111.

18 Guerra J y Huamani H. 1995. Caracterización edafoclimática del hábitat de las orquídeas. Tingo Maria-Perú: Universidad Nacional Agraria de la Selva. 40 pp.

19 Hijmans R, Schreuder M, De la Cruz,M y Rojas E. 2001. Computer tools for spatial analysis of plant genetic resources data: DIVA-GIS. Plant Genetic Resources Newsletter 27: 15-19.

20 Johnson T y Kane M. 2007. Asymbiotic germination of ornamental Vanda: in vitro germination and development of tree hybrids. Plant Cell Tissue and Organ Culture. 91: 251-261.

21 Jiménez, C. 2011. Orquídeas en el departamento del Meta. Villavicencio: Colombia. 88 pp.

22 Martínez S, Bonilla M y López H. 2015. Lista de Orchidaceae de Santander y comentarios sobre sus especies endémicas. Revista de la Facultad de Ciencias Básicas. 11 (2): 54-111.

23 Knudson, L. 1921. La germinación no simbiótica de las semillas de orquídeas. Boletín de la Real Sociedad Española de Historia Natural. $21: 250-260$. 
24 López, H. 2011.Orquídeas nativas de Santander. Gobernación de Santander. 319 pp.

25 Ortiz P y Uribe C. 2014. Orquídeas, tesoro de Colombia (A-D). Editorial Da Vinci Publicidad y Medios \& cía. S. En. C. 1-397 pp.

26 Pabón-Caicedo J, Eslava-Ramírez J y GómezTorres R. 2001. Generalidades de la distribución espacial y temporal de la temperatura del aire y precipitación en Colombia. Meteorología Colombiana. 47-59.

27 Pedroza-Manrique J. 2009. Efecto de carbón activado, ácido indolacético (AIA) y bencil amino purina (BAP) en el desarrollo de protocormos de Epidendrum elongatum Jacq bajo condiciones in vitro. Revista Colombiana de Biotecnología. 11 (1): 17-32.

28 Quiroga D, Martínez M y Larrea D. 2010. Sistemas de polinización de cinco especies de orquídeas creciendo bajo condiciones de invernadero. Ecología en Bolivia. 45(2): 131-137.

29 Rodríguez D. 2010. Caracterizaciones biológicas en la hacienda Macondo (Mapiripán, Meta). Orinoquia. 14(1): 18-27.

30 Rodríguez L, González R, Alvarado K y Telles E. 2007. Germinación asimbiótica in vitro de semillas de orquídeas silvestres. Biotecnología vegetal. 7(3): 139-142.
31 Salazar S. 2012. Germinación asimbiótica de semillas y desarrollo in vitro de plantulas de Cattleya medelii Dombrain (Orchidaceae). Acta Agronómica. 61(1): 69-78.

32 Salazar S y Orlando G. 2012. Evaluación del efecto de dos suplementos orgánicos en la germinación in vitro de orquídeas nativas de la provincia de Pamplona, Colombia. Revista Colombiana de Biotecnología. 24(1): 53-59.

33 Valencia J. 2014. Las orquídeas de San José (Santander, Colombia). Universidad Nacional de Colombia, Sede Bogotá. 307 pp.

34 Valencia R, Lobo M y Ligarreto G. 2010. El estado del arte de los recursos genéticos vegetales en Colombia: sistemas de bancos de germoplasma. Corpoica, ciencia tecnología agropecuaria. 11(1): 85-94. 